\title{
Investigation of Microstructural and Mechanical Properties of Zirconium Carbide Reinforced Aluminum Matrix Nanocomposites
}

\author{
H. CUG* AND O. ZENGIN \\ Karabuk University, Department of Mechanical Engineering, Karabuk, Turkey
}

\begin{abstract}
This study aims to investigate the effect of zirconium carbide $(\mathrm{ZrC})$ nanoparticles on mechanical performances of pure aluminum. Composites $\mathrm{Al}-0.5 \mathrm{ZrC}, \mathrm{Al}-1 \mathrm{ZrC}, \mathrm{Al}-2 \mathrm{ZrC}$ were fabricated by powder metallurgy. Hardness test was performed for all specimens. Compression test was conducted at room temperature. Results clearly show that homogenously distribution of nanoparticles was achieved up to $1 \mathrm{wt} \%$ reinforcement addition according to the scanning electron microscope results. The hardness of pure aluminum was increased significantly. Compression strength was also improved considerably with the addition of nano-reinforcements. Al-1ZrC composite showed best performance among the samples.
\end{abstract}

DOI: 10.12693/APhysPolA.135.870

PACS/topics: powder metallurgy, SEM, nanocomposites, mechanical properties, carbides

\section{Introduction}

Aluminum-based nanocomposites are widely used in various industries due to their good physical and mechanical properties. The addition of hard ceramic particles such as zirconium carbide ( $\mathrm{ZrC}$ ) into aluminum alloys will enhance wear resistance. These particles can be used on micron and nanoscale scales [1,2]. Among the ceramic particles, nano- $\mathrm{ZrC}$ is a very suitable material for producing Aluminum matrix composites because of its high modulus, hardness and wear resistance. Gotman et al. [3] investigated the compression properties of $\mathrm{TiC} / \mathrm{Al}$ and $\mathrm{TiB} / \mathrm{Al}$ composites, and reported that the yield stress of the $\mathrm{TiB}_{2} / \mathrm{Al}$ composite is higher than that of the $\mathrm{TiC} / \mathrm{Al}$ composite by the temperature increase.

Nanocomposites are produced using solid-state methods, semi-solid methods, and molten methods. Nonuniform reinforcement could lead to reduced strength and toughness of the composites. Generally, agglomeration occurs during casting due to density difference and surface tension of the melt. Solid-state processes such as powder metallurgy are used to produce composites with high mechanical properties as they provide a homogeneous distribution of the reinforcing phase fraction in the matrix material [4]. Previous studies [5, 6] had shown that a variety of composites with a more uniform distribution in a matrix with nano-sized reinforcing particles can be synthesized by high-energy ball milling. There is an insufficient knowledge on the production and investigation of $\mathrm{Al}$ matrix composites strengthened with ZrC particles using the $\mathrm{P} / \mathrm{M}$ method. In this paper, the role of $\mathrm{ZrC}$ hard nano-sized particle reinforcement on the

*corresponding author; e-mail: hcug@karabuk.edu.tr density, hardness, and mechanical properties was investigated. These composites were characterized using SEM and EDX methods. The change in mechanical properties was determined by microhardness measurement and compressing tests.

\section{Experimental procedure}

Aluminum powder (99.9\% purity and 40-50 $\mu \mathrm{m}$ size ranges) and Zirconium Carbide powder (99.9\% purity and 50-60 nm size ranges) were supplied from Nanografi Co. Ltd. in Turkey. Composites were fabricated by powder metallurgy technique after mechanical alloying of powders. Mechanical alloying was performed at $300 \mathrm{rpm}$ for $180 \mathrm{~min}$ with 10:1 ball to powder weight ratio. Then, the composite powder was pressed in graphite mold (15 mm diameter and $15 \mathrm{~mm}$ height) under $45 \mathrm{MPa}$ pressure at $530^{\circ} \mathrm{C}$ in hot press test machine. High purity argon was used in order to prevent oxidation. Sintering process was also carried out on the same device at $530^{\circ} \mathrm{C}$ for 1.5 hours.

Field emission scanning electron microscope (Carl Zeiss Ultra Plus) equipped with EDX was used to examine the microstructure of composite. Experimental densities of specimens were calculated according to the Archimedean principle. Vickers microhardness test were performed for the produced composites using $300 \mathrm{~g}$ of loading and $15 \mathrm{~s}$ of dwelling time. The compression specimens were cylinders with dimensions of $\varnothing 15 \mathrm{~mm} \times 15 \mathrm{~mm}$. Compression tests were conducted at $600 \mathrm{kN}$ Zwick Roell test machine. The compression rate was $1 \mathrm{~mm} / \mathrm{min}$.

\section{Results and discussion}

Five measurements were taken for each sample and average of hardness and density results belonging to the composites are presented in Table I. Since ZrC has a theoretical density of 6.73 [7], the density of the composite 
increases with the addition of $\mathrm{ZrC}$. However, there was a slight decrease in density with the increase of the reinforcement amount. This is due to the adverse effect of $\mathrm{ZrC}$ on compressibility.

TABLE I

Density and hardness results of composites.

\begin{tabular}{c|c|c}
\hline \hline $\begin{array}{c}\text { ZrC content } \\
{[\mathrm{wt} \%]}\end{array}$ & $\begin{array}{c}\text { Density } \\
{\left[\mathrm{g} / \mathrm{cm}^{3}\right]}\end{array}$ & $\begin{array}{c}\text { Hardness } \\
{[\mathrm{HV}]}\end{array}$ \\
\hline 0 & 2.4570 & 27.4 \\
0.5 & 2.5626 & 31.5 \\
1 & 2.5430 & 35.3 \\
2 & 2.5378 & 30.7
\end{tabular}

Hardness performance is improved significantly with the addition of $\mathrm{ZrC}$ nanoparticles. This can be attributed that there might be an obstacle which can effect dislocation movement due to the presence of harder reinforcements [8]. However, there is slightly decrease over $1 \mathrm{wt} \%$ $\mathrm{ZrC}$ content. This is because agglomerations of $\mathrm{ZrC}$ particles at grain boundaries (shown in Fig. 1b) can cause weak chemical bonding between aluminum and reinforcement material.
As is shown in Fig. 1a, macro defects can be seen in some regions. It was observed also, that there is partly agglomeration for $2.0 \mathrm{wt} \% \mathrm{ZrC}$ reinforced composite while homogeneous distribution was obtained for $0.5 \mathrm{wt} \% \mathrm{ZrC}$ reinforced composite. As expected, the matrix contains aluminum and very little amount oxygen in micropores, as is shown in Fig. 1b. The agglomeration of nano $\mathrm{ZrC}$ particles can be seen especially in grain boundaries.

The engineering stress-strain curves of the compression tests of all test specimens are shown in Fig. 2. Figure 2 reveals that the yield and ultimate stress of pure $\mathrm{Al}$ increases with the incorporation of nano $\mathrm{ZrC}$ particles until $2 \mathrm{wt} \%$. The addition of $2 \% \mathrm{ZrC}$ exhibits lowest compressive yield strength due to the lack of homogeneous distribution and overgrowth in the grain boundary. The yield and ultimate stress of the composite may also be greater than unreinforced $\mathrm{Al}$ because of increased dislocation density and reduced grain size [9]. The restricted dislocation movement might play important role to determine mechanical performance of pure aluminum also [10]. However, after $25 \%$ deformation due to ductile structure, pure $\mathrm{Al}$ compressive strength increases gradually compared to composites.
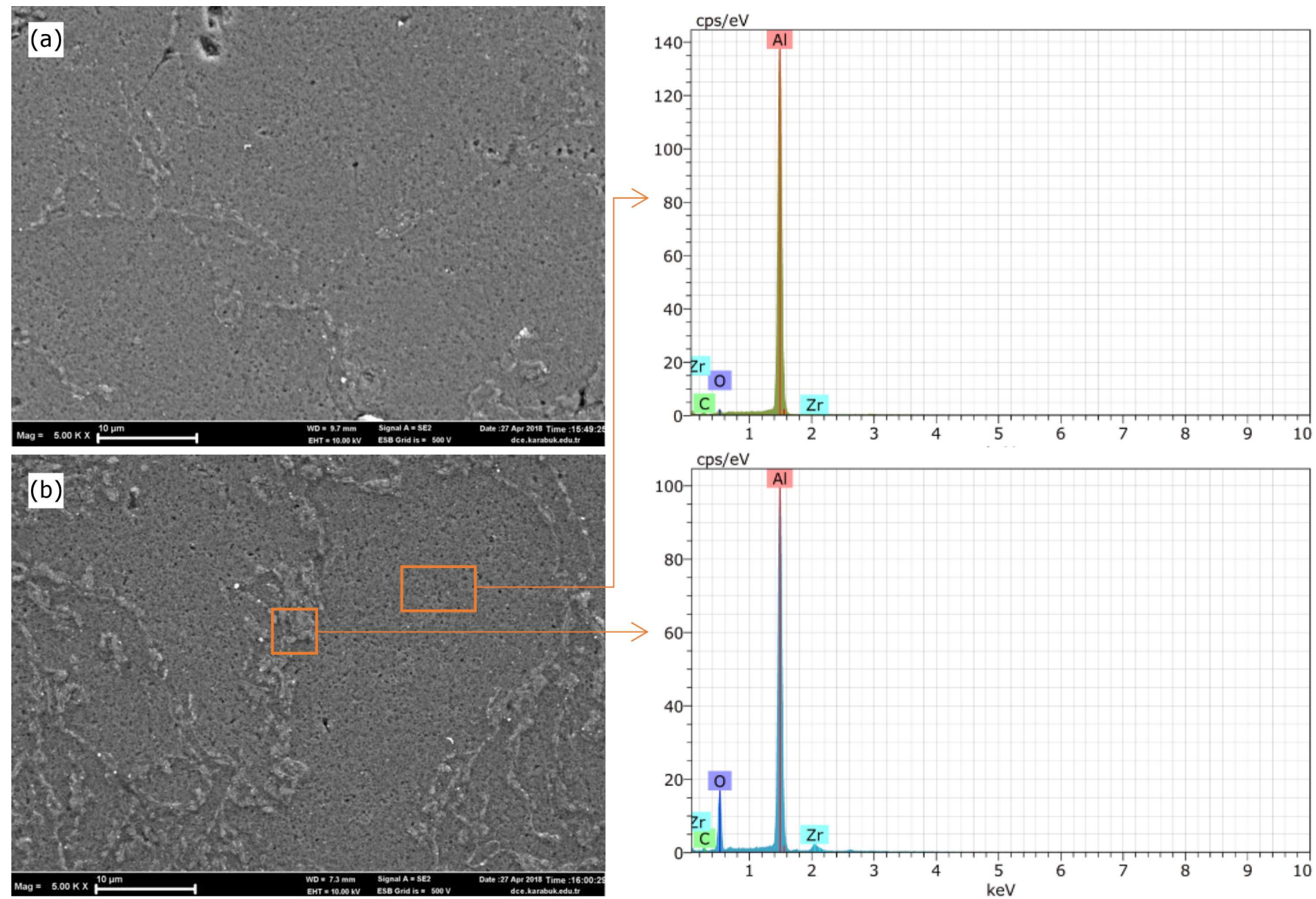

Fig. 1. SEM images of Al-0.5ZrC (a), Al-2ZrC and EDX analysis of Al-2ZrC reinforced composites (b). 


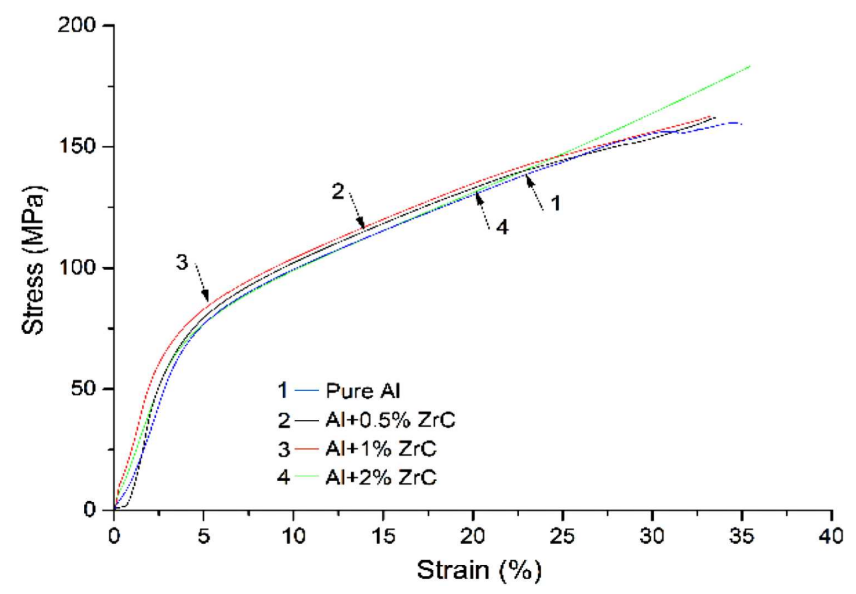

Fig. 2. Compression test results of specimens.

\section{Conclusion}

$\mathrm{ZrC}$ reinforced $\mathrm{Al}$ matrix composites were fabricated successfully using mechanical alloying and hot press procedures. Microstructure is generally free of defects and macro porosities. Homogenously distribution could be seen up to $1 \mathrm{wt} \%$ nano-reinforcement addition but there are agglomerations for $2 \mathrm{wt} \%$ amount which can effect mechanical properties. Hardness of pure aluminum is improved considerably with the addition of $\mathrm{ZrC}$ nanoparticles up to $1 \mathrm{wt} \%$ amount. Al-1ZrC composite has highest compression strength among the fabricated samples.

\section{Acknowledgments}

This work is supported by the Scientific Research Projects of Karabuk University (Grant No: KBUBAP18-Yl-004) in Turkey.

\section{References}

[1] Y. Saberi, S.M. Zebarjad, G.H. Akbari, J. All. Comp. 484, 637 (2009).

[2] I. Estrada-Guel, C. Carreńo-Gallardo, D.C. MendozaRuiz, M. Miki-Yoshida, E. Rocha-Rangel, R. Martínez-Sánchez, J. All. Comp. 483, 173 (2009).

[3] I. Gotman, M.J. Koczak, E. Shtessel, Mat. Sci. Eng. A 187, 189 (1994).

[4] G. Abouelmagd, J. Mat. Proc. Technol. 155, 1395 (2004).

[5] B. Prabhu, C. Suryanarayana, L. An, R. Vaidyanathan, Mat. Sci. Eng. A 425, 192 (2006).

[6] I. Özdemir, S. Ahrens, S. Mücklich, B. Wielage, Pract. Metall. 45, 136 (2008).

[7] K. Schönfeld, H.P. Martin, A. Michaelis, J. Adv. Ceram. 6, 165 (2017).

[8] M.E. Turan, Y. Sun, Y. Akgul, Fuller. Nanotub. Carb. Nanostr. 26, 130 (2018).

[9] Z. Zhang, B.Q. Han, D. Witkin, L. Ajdelsztajn, E.J. Laverna, Scr. Mater. 54, 869 (2006).

[10] M.E. Turan, Y. Sun, Y. Akgul, J. All. Comp. 740 , 1149 (2018). 